\title{
A IMPORTÂNCIA DA ORGANIZAÇÃO DE EVENTOS ACADÊMICOS NA FORMAÇÃO DO BIÓLOGO: A INICIATIVA DO BIOVERTENTES
}

\author{
Joicelene Regina Lima da Paz ${ }^{1}$ \\ Marcus Vinicius Peralva dos Santos ${ }^{2}$ \\ Wagner Pereira Silva ${ }^{3}$ \\ André Luiz da Costa Moreira ${ }^{4}$ \\ Clarissa Cunha Santana ${ }^{5}$
}

\begin{abstract}
RESUMO: A extensão universitária é o processo educativo, cultural e científico que, articulado ao ensino e à pesquisa de forma indissociável, viabiliza a relação transformadora entre a universidade e a sociedade. As atividades de extensão assumem um papel de grande importância no processo da comunicação científica, fomentando o desenvolvimento da Ciência, bem como atuam no aperfeiçoamento e na qualificação de recursos humanos. Nesse contexto, apresentamos o relato da experiência decorrente da organização do BioVertentes, descrevendo os resultados alcançados e a avaliação obtida a partir da análise dos questionários anônimos preenchidos pelos participantes. O evento ocorreu entre março e abril de 2011, no Centro Universitário Jorge Amado, em Salvador-BA, abrangendo um público superior a 300 pessoas. Foram ofertados sete minicursos com carga horária total de seis horas cada. A inscrição ocorreu mediante a doação de alimentos não perecíveis, encaminhados a uma instituição beneficente. De maneira geral, o evento foi bem avaliado pelo público e, para as futuras edições, alguns aspectos como divulgação, apoio, patrocínio e palestrantes podem ser melhorados, de forma a torná-lo um evento acadêmico anual institucional do curso, aberto ao público de estudantes e profissionais da área.
\end{abstract}

PALAVRAS-CHAVE: Avaliação. Biólogo. Experiência. Extensão. Minicursos.

The importance of academic event organization in the formation of Biology students:

BioVertentes initiative

\begin{abstract}
Linked to teaching and scientific research, academic extension is the educational, cultural and scientific process that enables the transforming relation between university and society. Scientific extension activities play a major role in the process of scientific communication, promoting the development of science, as well as work in human resource improvement and qualification. We present the experience report about the organization of BioVertentes, describing the results achieved and the assessment done by the participants thought the analysis of anonymous questionnaires completed by them. The event took place in the Jorge Amado University Center, in Salvador (Bahia state), between March and April 2011, in which participated more than 300 peoples. Seven short courses, with six hours each, were offered. Those who were interested in take part in the event should donate non-perishable food, which

\footnotetext{
Mestre em Botânica pela Universidade Estadual de Feira de Santana, professora adjunta no curso de Bacharelado em Enfermagem da Faculdade São Salvador (joicelene.lima@yahoo.com.br).

Doutorando em Geologia Marinha na Universidade Federal da Bahia (biologo aprendiz@yahoo.com.br).

Mestre em Zoologia pela Universidade Estadual de Feira de Santana (wagner.sillva@yahoo.com.br). Aberta do Brasil (moreirabiologo@yahoo.com.br).

5 Mestranda em Biotecnologia em Saúde e Medicina Investigativa no Centro de Pesquisas Gonçalo Moniz da Fundação Oswaldo Cruz (clarissacunha2006@yahoo.com.br).
}

4 Mestre em Botânica pela Universidade de Brasília, professor titular no curso de Pedagogia da Faculdade Alvorada e tutor de Botânica da Universidade


was donated to charity. Overall, the event was well rated by the public; for future editions, some aspects, such as disclosure, support, sponsorship and speakers, may be improved, aiming to make this an annual academic institutional event, opened to students and professionals of the area.

KEYWORDS: Biologist. Evaluation. Experience. Extension. Short Courses.

\section{INTRODUÇÃO}

Os eventos científicos vêm se consolidando como um importante espaço de dinamização de discussões e avanços de pesquisas de uma determinada especialidade, promovendo a integração do ensino e o desenvolvimento cultural e científico na sociedade. Os diversos tipos de encontros científicos variam, principalmente, em abrangência e objetivos, mas, de maneira geral, exibem uma estrutura semelhante que adquire singularidade de acordo com a dimensão projetada (CAMPELLO, 2000).

Apesar das dificuldades de realização e apoio às iniciativas científicas, sobretudo às atividades de caráter local e regional, esses eventos vêm adquirindo importância e frequência crescentes na comunidade científica - sobretudo por meio da divulgação de resultados e impactos alcançados - e, cada vez mais, são reportados sob a forma de registros e publicações (CAPUCCI et al., 1999; GOULART et al., 2006; FERREIRA, 2007; CARVALHO et al., 2008; CARVALHO-SOUZA, 2008; LACERDA et al., 2008), servindo de incentivo para a participação de maior público e para o surgimento de outras iniciativas acadêmicas.

No campo de atuação das Ciências Biológicas, espera-se que o profissional biólogo desempenhe um papel essencialmente construtivo e estruturador na sociedade, uma vez que, ao produzir, discutir e difundir conhecimento, ele contribui para o desenvolvimento e para a transformação social (UNISANTA, 2011). Diante disso, espera-se que, para atender a essas atribuições, a formação acadêmica do biólogo seja ampla, flexível e, principalmente, de caráter interdisciplinar, atribuindo, assim, importância às atividades extracurriculares em consonância com as disciplinas cursadas e os conhecimentos já obtidos em sala de aula para a formação profissional e intelectual dos estudantes (LACERDA et al., 2008).

Nesse contexto, idealizou-se a primeira edição do BioVertentes, criado a partir da necessidade de cursos temáticos na formação complementar do biólogo. O evento foi organizado a partir da iniciativa de um grupo de egressos do curso de Ciências Biológicas do Centro Universitário Jorge Amado (Unijorge), que ansiava partilhar dos conhecimentos adquiridos durante a graduação e a pós-graduação e promover o intercâmbio científico-acadêmico. Dessa maneira, o evento visou à discussão e à troca de experiências, ideias e conhecimentos entre professores, pósgraduandos e graduandos, bem como à promoção do amadurecimento e da responsabilidade no planejamento e na organização de atividades de cunho científico aos alunos de pós-graduação.

Diante do exposto, este texto relata a experiência e apresenta os principais resultados alcançados na organização do BioVertentes, avaliando as atribuições de importância e as justificativas, a partir da análise dos questionários preenchidos por palestrantes, participantes e comissão organizadora, 
de forma a fomentar outras iniciativas acadêmicas que promovam o incentivo, a socialização, a divulgação e a popularização da Ciência.

\section{A temática}

"As Vertentes da Biologia", tema escolhido para a primeira edição do evento, baseou-se nos pressupostos de que as Ciências Biológicas resumem-se em uma ciência múltipla e bastante heterogênea e de que o profissional da área tem por lei (Lei 6.684) atribuições diversas, como formular e elaborar estudo, projeto ou pesquisa científica básica e aplicada, nos vários setores da Biologia ou a ela ligados, como preservação, saneamento e melhoramento do meio ambiente (BRASIL, 1998). A legislação ainda prevê que os cursos de Ensino Superior -públicos ou privados - podem e devem contribuir de maneira significativa na política de inserção da pesquisa e da qualidade acadêmica dos cursos, estimulando e realizando atividades extracurriculares e extensionistas como estratégia didática para garantir a interação teoria-prática, uma sólida formação básica inter e multidisciplinar (BRASIL, 1998), assim como se propôs o BioVertentes.

Na cidade de Salvador-BA, existem, atualmente, quatro instituições que oferecem o Curso Superior de Ciências Biológicas (Licenciatura e/ou Bacharelado), sendo três delas privadas e uma pública. A maioria delas promove, periodicamente, eventos acadêmico-científicos e extensionistas organizados por alunos e voltados à formação complementar dos profissionais da área e de outras correlatas. Entretanto, essas atividades estão especialmente concentradas em setembro, mês de comemoração do Dia do Biólogo, sendo ocasionais em outros períodos do ano. Assim, em virtude dessa lacuna temporal e entendendo a necessidade de mais iniciativas que supram a necessidade de engajamento e formação do graduando em Biologia, a primeira edição do BioVertentes concentrou suas atividades entre os meses de março e abril de 2011, no Campus Paralela da Unijorge, em Salvador-BA.

\section{Sobre as atividades do evento}

O BioVertentes foi idealizado a fim de fomentar a participação de egressos institucionais, atualmente pós-graduandos, como palestrantes, ministrando minicursos da sua área de atuação, classificados dentro dos principais eixos norteadores, a saber: Botânica, Etnoecologia, Meio Ambiente e Zoologia.

Nessa primeira edição, priorizou-se a participação do público institucional:alunos e comunidade externa (composta predominantemente de ex-alunos), o que atende em parte aos objetivos do Projeto Político Pedagógico(PPP) do curso de Ciências Biológicas da instituição, narealização de atividades de extensão.

As atividades acadêmico-científicas foram realizadas durante 20 dias não consecutivos entre os meses de março e abril de 2011. A inscrição dos participantes foi efetivada mediante a doação simbólica de $2 \mathrm{~kg}$ de alimentos não perecíveis por minicurso participado, totalizando, ao final, $267 \mathrm{~kg}$ de alimentos arrecadados e posteriormente doados às obras assistenciais da Instituição Mansão do Caminho, localizada em uma região carente da capital baiana, próxima à Unijorge. 
Para cada minicurso divulgado, foram ofertadas 25 vagas nos períodos matutino e vespertino, oportunizando a participação de maior público em períodos distintos. A programação da iniciativa foi organizada segundo cinco eixos norteadores por dia, ao qual correspondiam todas as atividades sequentes.

Os minicursos realizados proporcionaram troca de experiências e vivências dos profissionais que atuam naárea, além de perspectivas e demandas para o mercado de trabalho, incentivo ao desenvolvimento de pesquisa e adesão de novos profissionais à área científica, promovendo a interação entre a comunidade acadêmica e aqueles que já se encontram em uma etapa mais aprofundada da profissão. Dessa forma, buscou-se alcançar nível de reflexão e possibilidades de atuação para o público participante.

A realização do evento contou apenas com a colaboração de voluntários (ex-alunos institucionais), os quais arcaram com todas as demandas dos participantes e palestrantes, tornando ainda mais importante a interação entre alunos de graduação e egressos. Entretanto, apesar do bom desempenho do evento, é importante ressaltar a necessidade de um apoio mais sólido e substancial à iniciativa, uma vez que nesse panorama de voluntariado muitas adversidades são relatadas na realização de atividades acadêmico-científicas, como em Carvalho-Souza et al. (2008), especialmente quando se trata de primeiras edições, assim como foi o caso do BioVertentes. Nesse aspecto, enfatiza-se que essa iniciativa extensionista recebeu total apoio da coordenação do curso de Biologia da Unijorge, além de outros setores e núcleos da instituição, em menor proporção.

Minicursos realizados Todos os sete minicursos ofertados foram realizados, formando dez turmas (entre os turnos matutino e vespertino), com carga horária total de seis horas/minicurso (Figura 1).

Figura 1 - Minicursos realizados no BioVertentes, no Centro Universitário Jorge Amado, entre março e abril de 2011.

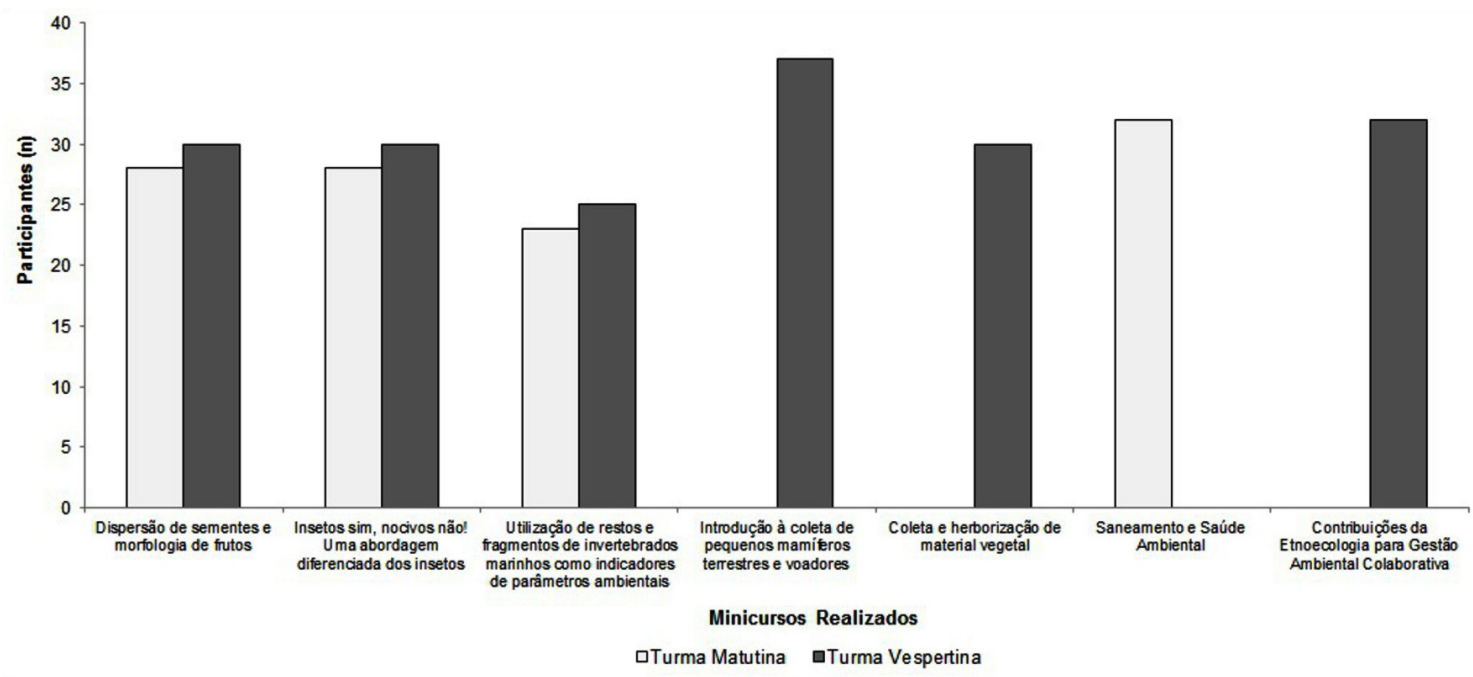

Fonte: Os autores.

Os palestrantes vieram de três instituições da Bahia - Universidade Estadual de Feira de Santana (UEFS), Universidade Federal da Bahia (UFBA) e Associação Classista de Educação da Bahia 
(ACEB) - e da Universidade de Brasília (UnB).

Os minicursos configuram-se em uma experiência importante no âmbito acadêmico, inserindo o pós-graduando no contexto profissional da transmissão de conhecimento e vivências nas diversas áreas de atuação. E, ainda, possibilitam a articulação da sociedade, aqui representada pelos profissionais já atuantes, com a comunidade acadêmica, o que caracteriza a extensão universitária, que se constitui como um processo educativo, cultural e científico que articula o ensino e a pesquisa de forma indissociável e viabiliza a relação transformadora entre Universidade e Sociedade (FORPROEX, 2012).

Iniciativas extensionistas que reúnem profissionais ou estudantes recém-formados são experiências bem consolidadas em outras instituições, sobretudo em Instituições Superiores de Ensino Públicas da Bahia (a exemplo dos diversos Cursos de Verão, Inverno, Primavera, dentre outros de várias áreas da ciência), mas vêm ganhando espaço também em instituições privadas, como o relato de experiência em questão. No retorno de docentes e discentes à Universidade, seus conhecimentos e suas experiências conferem um aprendizado que, submetido à reflexão teórica, será acrescido ao conhecimento acadêmico. Esse fluxo, que estabelece a troca de saberes sistematizados acadêmicos e populares -, terá como consequências: a produção do conhecimento resultante do confronto com a realidade brasileira e regional, a democratização do conhecimento acadêmico e a participação efetiva da comunidade na atuação da Universidade (FORPROEX, 2012).

No total, o evento contou com a participação de 314 pessoas, sendo público inscrito (n = 295), palestrantes $(n=07)$ e integrantes da comissão organizadora $(n=05)$. Embora o público almejado fosse alunos da Unijorge, alunos de outras instituições também demonstraram interesse nas inscrições. Dentre os inscritos, os graduandos foram a maioria do público, com 95,3\%, em relação à comunidade externa, com somente 4,7\%. Comportamento este provavelmente explicado pela curiosidade sobre diferentes áreas da Biologia, bem como a necessidade inerente da definição de uma delas para o aperfeiçoamento profissional. As demandas encontradas na matriz curricular do curso, que algumas vezes não conseguem ser supridas pelo plano educacional dentro do período da graduação, também podem ser apontadas como gatilho impulsionador do interesse dos estudantes nos minicursos ofertados pelo Biovertentes.

Além disso, para um público essencialmente de graduandos, os benefícios e as vantagens na participação de ações científicas e extensionistas referem-se, principalmente, à oferta de subsídios técnico-práticos e científicos que aprimoram conhecimentos, habilidades e atitudes, possibilitando a abertura de novas perspectivas de aprendizagem e um olhar mais cuidadoso e atento sobre um assunto de interesse pessoal e/ou profissional-científico (UNIVILLE, 2014). De acordo com Bardagi et al. (2003), os alunos das áreas biológicas demonstram elevado interesse na realização de atividades acadêmicas, sobretudo quando reconhecem na formação complementar - atividades extracurriculares, como palestras, cursos, seminários, congressos e pesquisas - um momento imprescindível que, além de propiciar maior convívio no ambiente acadêmico, desperta um maior envolvimento no estudante através da troca de ideias e experiências, algo fundamental para compreender a importância do atual ambiente de transformação da 
sociedade para sua futura profissão (SILVA; VASCONCELOS, 2006; LACERDA et al., 2008).

\section{Avaliação das atividades pelos participantes}

Foram distribuídos questionários a serem respondidos anonimamente, visando: conhecer o público participante, suas opiniões sobre a organização e a repercussão do evento; obter uma avaliação dos cursos e dos palestrantes; e sondar o interesse em participar de uma nova edição do BioVertentes.

Sendo composto por 11 questões, o questionário, distribuído aos participantes e recolhido ao final de cada atividade acadêmica, foi utilizado como instrumento de coleta de dados, com três opções de resposta: "sim", "parcialmente" e "não". No questionário avaliativo, também houve um espaço livre, destinado aos demais comentários e impressões, por entendermos serem importantes as sugestões, as críticas e os elogios ao evento, palestrante e/ou comissão organizadora. A avaliação e análise de conteúdo dos dados provenientes dos questionários seguiram a técnica adaptada de Bardin (2009), usualmente utilizada para análise dos dados em outras publicações do mesmo gênero (CARVALHO-SOUZA et al., 2008; LACERDA et al., 2008; BIONDI; ALVES, 2011).

Os itens avaliados foram agrupados quanto a três aspectos: temática e programação científica; interesse e/ou disponibilidade de participar de edições futuras na área; e organização geral do evento. De acordo com Carvalho-Souza et al. (2008), o conhecimento e a análise dos dados provenientes da avaliação das ações ocorridas interessam não apenas à coordenação do evento e do curso, mas também a toda a comunidade acadêmica que participou e prestigiou o BioVertentes.

Ao final das ações acadêmicas, obtivemos o retorno espontâneo de 161 fichas de avaliação preenchidas, não havendo diferenças significativas nas respostas entre as categorias de participantes. No contexto geral, o evento teve boa aceitação entre o público presente, dentre os quais $81 \%$ o consideraram produtivo e com alguma contribuição para a formação profissional. A divulgação das atividades também foi bem avaliada, com $81 \%$ dos inscritos considerando-a boa; $18 \%$, parcialmente satisfatória e $1 \%$, ruim. Nesta primeira edição, a programação contou com um público frequente e significativo, reluzindo boa repercussão institucional. Os resultados dessa avaliação sugerem que o evento conseguiu atingir seus objetivos primordiais, divulgando as perspectivas e as possibilidades nas principais áreas de atuação das Ciências Biológicas e, o mais importante, oferecendo aos participantes atividades integradoras, que contemplavam seus interesses (SILVA; VASCONCELOS, 2006).

No que tange à temática e à programação científica, 98\% dos participantes as consideraram boas, e uma pequena parcela (2\%), parcialmente satisfatórias. Assim como a satisfação $(85 \%)$ quanto à estrutura e à forma de organização dos minicursos em semanas e em turnos diferentes, ao passo que $14 \%$ declararam-se parcialmente satisfeitos e 1\% insatisfeitos. A carga horária total dos minicursos e a sua distribuição também agradaram ao público $(85 \%)$, sugerindo que os cursos de extensão universitária, geralmente acadêmicos e com pequena carga-horária, destinam-se a complementar o conhecimento em áreas específicas e objetivam difundir e atualizar conhecimentos, sendo abertos à participação da comunidade em geral, seja ela acadêmica ou não. 
Adicionalmente, no espaço livre destinado aos demais comentários, houve pedidos e sugestões para a realização de cursos de extensão com maior carga horária e diversidade de temáticas nos próximos eventos. Essas sugestões serão consideradas na organização de outras edições, mas, sobretudo, demonstram o interesse e a vontade dos participantes no aprofundamento das áreas dos minicursos dos quais participarem ( $85 \%$ do total de participantes efetivos).

Quanto às áreas de interesse mais ressaltadas pelos alunos, Zoologia (33\%) e Botânica (33\%) foram as mais ressaltadas, seguidas por Biologia Marinha (19\%)e as demaisáreas, que, em conjunto, somam 15\%.

O quesito organizacional foi avaliado como muito bom entre os participantes (71\%). A boa aceitação do público acadêmico, tanto do ponto de vista organizacional quanto da temática, pode ser considerada bom indício de satisfação dos ouvintes participantes, sendo espontaneamente destacada a intenção de participar de outras atividades acadêmicas, como essa realizada na Unijorge. Complementarmente, houve registros elogiando a comissão organizadora pela iniciativa da proposta do evento e do valor simbólico da inscrição.

Segundo Lacerda et al. (2008), os eventos científicos assumem um papel de grande importância no processo da comunicação, na medida em que a transmissão de ideias e fatos novos chega ao conhecimento da comunidade científica de maneira mais rápida que aquelas veiculadas pelos meios formais de comunicação. Dessa maneira, iniciativas acadêmicas, como o BioVertentes, propõem-se a fomentar o desenvolvimento da Ciência, bem como atuam no aperfeiçoamento e na qualificação de recursos humanos. Essas iniciativas também podem ser utilizadas para o aprimoramento dos conteúdos e contextos adquiridos na formação profissional, sendo anteriores ou posteriores à graduação, uma vez que a experiência e o conhecimento adquirido em cursos extensionistas servem para a qualificação profissional daqueles que participam, capacitando-os e certificando-os ao exercício das atividades as quais se propõem e aprimorando o senso crítico e o modo de agir dos seus participantes (BIONDI; ALVES, 2011).

Constatou-se também, a partir da análise dos questionários, que alguns alunos demonstraram interesse em participar de outras atividades na área dos minicursos assistidos, na condição de grupos de estudos, grupos de iniciação científica, apoio e ajuda voluntária em projetos e coletas. Justificam, em sua maioria, que, por meio da prática, seria mais interessante a assimilação e o aprofundamento do conteúdo teórico desenvolvido no minicurso assistido. Assim, pôdese dimensionar, parcialmente, o impacto da realização do evento na modulação do interesse no aprendizado e na conscientização da importância deste tipo de atividade na formação do profissional, não sendo somente limitada ao conteúdo ministrado em sala de aula, mas também no intercâmbio de conhecimento entre os próprios estudantes, e com toda a comunidade acadêmica.

Em comparação às edições de outros eventos de Ciências Biológicas de outras instituições de maior porte e com datas já consolidadas no calendário local do município de Salvador, a primeira edição do BioVertentes exibiu uma aceitação proporcionalmente comparável aos demais, dentro da estrutura organizacional e de público diversificado.

Por fim, assim como afirmado por Carvalho-Souza et al. (2008), ressalta-se que, ainda por tratarse da primeira edição, as deficiências que surgiram servirão como aprendizado e base para o 
aprimoramento das próximas edições. Pela extensão, a comunidade acadêmica tem a possibilidade de, na sociedade, elaborar e vivenciar a práxis do conhecimento adquirido, promovendo uma postura que extrapola a formação profissional do estudante, propiciando-lhe uma visão mais globalizada de conhecimento, a partir da conscientização das realidades vivenciadas por diferentes comunidades e do seu papel enquanto sujeito social (MARTINS, 2008). Para Fischer et al. (2012), o aluno de Biologia sinaliza a pouca experiência e a dificuldade em estabelecer contatos profissionais como os principais fatores inibitórios para a sua inserção no mercado de trabalho.

Resumidamente, extensão é a atividade acadêmica por meio da qual a Universidade, de modo direto, compartilha com a sociedade, cultura, conhecimento e informação. Assim, extensão, ensino e pesquisa constituem as bases para o sucesso de uma formação acadêmica sólida necessária, não somente ao biólogo, mas também às demais profissões com grande viés acadêmico e/ou científico. Por isso, as universidades precisam valorizar e fomentar cada vez mais as atividades de extensão, estabelecendo apoios mais sólidos aos cursos, a fim de promover maiores oportunidades aos docentes, discentes, funcionários e à comunidade externa de forma geral de praticarem a cidadania. Recomenda-se que outros cursos realizem pesquisas de avaliação dos seus projetos de extensão para servir de reflexão e enaltecer o papel da extensão na universidade.

Dessa forma, o evento possibilitou aos alunos não apenas adquirir novos conhecimentos teóricos e práticos, mas também estabelecer vínculo com egressos que já se encontram inseridos na área da educação e/ou pesquisa. Com base em tais dados, para edições futuras do BioVertentes e realização de outras atividades de extensão, os idealizadores das atividades irão desenvolver, de forma conjunta, novas ações de extensão - a exemplo do que ocorre em projetos de pesquisa -, as quais deverão englobar as mais variadas áreas do curso de Ciências Biológicas e, se possível, promover a interdisciplinaridade entre áreas em um único projeto, a fim de mostrar aos seus participantes a notável indissociabilidade entre ensino-pesquisa-extensão.

\section{CONSIDERAÇÕES FINAIS}

O BioVertentes representou uma iniciativa piloto de egressos encorajados pela ideia de promover uma atividade de extensão a partir de um espaço aberto às discussões, aos questionamentos e às novas perspectivas na área da Biologia, contribuindo, ainda, para o preenchimento das lacunas e necessidades da matriz curricular do curso.

Nesta primeira edição, priorizou-se a participação de graduandos e comunidade externa, na oferta de sete minicursos de palestrantes egressos, distribuídos em 10 turmas, atingindo um público de aproximadamente 300 participantes. Mediante as inscrições foram arrecadados 267 $\mathrm{kg}$ de alimentos não perecíveis, doados a uma obra assistencial carente. No contexto geral, as atividades extensionistas foram bem avaliadas pelo público por meio dos questionários, com índices de satisfação superiores a $80 \%$.

A realização dessa iniciativa possibilitou dimensionar a importância da extensão em vários âmbitos: na universidade, no curso de Biologia e na vida acadêmica e pessoal dos estudantes. 
Para as futuras edições, aspectos como divulgação, apoio, patrocínio e palestrantes podem ser potencializados, almejando, assim, a consolidação do evento no calendário institucional do curso, e fomentando a oferta de atividades extracurriculares aos graduandos e à comunidade externa, que se caracterizam pela indissociabilidade entre ensino-pesquisa-extensão.

\section{AGRADECIMENTOS}

À Coordenação do Curso de Ciências Biológicas do Centro Universitário Jorge Amado (Unijorge), representado pelo Prof. Dr. Edinaldo Luz das Neves, pelo apoio e pela colaboração. Aos diversos professores da Unijorge, que colaboraram com ideias, incentivo, apoio e divulgação das atividades, com especial referência à Profa. Dra. Camila Magalhães Pigozzo e à Profa. Me. Bernadete de Lurdes Oliveira Barbosa. Aos demais membros da comissão organizadora, Prof ${ }^{\mathrm{a}}$. Me. Mônica Costa de Abreu e o biólogo Arilson Reis Santos, pela participação e colaboração. A todos os colegas que participaram deste evento, seja na condição de monitor, palestrante ou ouvinte.

\section{REFERÊNCIAS}

BARDAGI, M. P.; LASSANCE, M. C. P.; PARADISO, A. C. Trajetória acadêmica e satisfação com a escolha profissional de universitários em meio de curso. Revista Brasileira de Orientação Profissional, São Paulo, v. 4, n.1-2, p. 153-166, dez. 2003.

BARDIN, L. Análise de conteúdo. Lisboa: Edições 70, 2009.

BIONDI, D.; ALVES, G. C. A extensão universitária na formação de estudantes do curso de Engenharia Florestal - UFPR. Revista Eletrônica do Mestrado em Educação Ambiental, Rio Grande, v. 26, p. 209-194, jan.-jun. 2011.

BRASIL. Decreto-Lei n ${ }^{\circ} 6.684$, de 3 de setembro de 1979. Regulamenta as profissões de Biólogo e de Biomédico, cria o Conselho Federal e os Conselhos Regionais de Biologia e Biomedicina, e dá outras providências. Diário Oficial [da] República Federativa do Brasil, Brasília, DF, 8 de abr. 1998. Seção 1, p. 6.009.

CAMPELLO, B. S. Encontros científicos. In: CAMPELLO, B. S.; CENDÒN, B. V.; KREMER, J. M. (Org). Fontes de informação para pesquisadores e profissionais. Belo Horizonte: Editora da UFMG, 2000.

CAPUCCI, P. F. et al. Um olhar sobre o VI Congresso Paulista de Saúde Pública. Saúde e Sociedade, São Paulo, v. 8, n. 2, p. 109-123, 1999.

CARVALHO, H. F. et al. Aos estudantes de iniciação científica que desejam participar do XIV Congresso da Sociedade Brasileira de Biologia Celular: livro de resumos. São Paulo: Sociedade Brasileira de Biologia Celular, 2008.

CARVALHO-SOUZA, G. F. et al. Importância da produção de eventos científicos na formação 
acadêmica: a experiência da Semeia. In: SEMANA DE MOBILIZAÇÃO (SEMOC), 11., 2008, Salvador. Anais... Salvador: Editora daUCSal, 2008.

FERREIRA, A. V. Relato sobre o $5^{\circ}$ Congresso Nacional do MST. Revista Discente Expressões Geográficas, Florianópolis, 2007.

FISCHER, M. L. et al. Percepção de carreira e projeto profissional de alunos do curso de Biologia. Revista Estudos de Biologia, Curitiba, v. 34, n. 82, p. 9-21, 2012.

FORPROEX. Política Nacional de Extensão Universitária. Manaus, 2012. Disponível em: em: <http://www.proec.ufpr.br/downloads/extensao/2012/legislacao/Politica $\% 20$ Nacional $\% 20$ de\%20Extensao\%20Universitaria\%20maio2012.pdf>. Acesso em: 4 mar. 2014.

GOULART, D. F.; ISSA, Y. S.M. M.; DENCKER, A. F. M. Eventos científicos: uma análise realizada no Intercom 2005, considerando organização e realização do evento - tabulação, interpretação e resultados. In: CONGRESSO BRASILEIRO DE CIÊNCIAS DA COMUNICAÇÃO, 29. 2006, Brasília. Resumos... Brasília: Editora da UnB, 2006.

LACERDA, A. L. et al. A importância dos eventos científicos na formação acadêmica: estudantes de Biblioteconomia. Revista ACB: Biblioteconomia em Santa Catarina, Florianópolis, v. 13, n. 1, p. 130-144, 2008.

MARCHIORI, P. Z. et al. Fatores motivacionais da comunidade científica para publicação e divulgação de sua produção em revistas científicas. In: SEMINÁRIO NACIONAL DE BIBLIOTECAS UNIVERSITÁRIAS, 1., 2006, Salvador. Anais... Salvador, 2006. Disponível em: <http://www.snbu2006.ufba.br/soac/papers.php>. Acesso em: 2 set. 2012.

MARTINS, E. F. Extensão como componente curricular: oportunidade de formação integral e de solidariedade. Ciências \& Cognição, Rio de Janeiro, v. 13, n. 2, p. 201-209, 2008.

SILVA, M. S.; VASCONCELOS, S. D. Extensão universitária e formação profissional: avaliação da experiência das Ciências Biológicas na Universidade Federal de Pernambuco. Estudos em Avaliação Educacional, São Paulo, v. 17, n. 33, p. 119-136, 2006. 